\title{
Subjective vs. Objective Urine Color: Effect of Hydration Status
}

\author{
Tory Edwards, Rebekah Belasco, Alfonso Joaquin Munoz, Vernon Rayo, Michael Buono*
}

School of Exercise and Nutritional Sciences, San Diego State University, San Diego, the United States

\author{
Email address: \\ mbuono@sdsu.edu (M. Buono) \\ ${ }^{*}$ Corresponding author
}

\section{To cite this article:}

Tory Edwards, Rebekah Belasco, Alfonso Joaquin Munoz, Vernon Rayo, Michael Buono. Subjective vs. Objective Urine Color: Effect of Hydration Status. Advances in Applied Physiology. Vol. 5, No. 2, 2020, pp. 19-23. doi: 10.11648/j.aap.20200502.12

Received: August 5, 2020; Accepted: August 24, 2020; Published: September 3, 2020

\begin{abstract}
Purpose: To investigate the validity of urine color as a metric of hydration status using CIE L*a*b* color space, as compared to the commonly used subjective 8-point scale. Methods: A total of 151 urine samples were collected from subjects $(\mathrm{N}=28)$ in various states of hydration. Urine osmolality and urine specific gravity (USG) were measured in each sample. Urine color was assessed by the subjective 8-point urine color scale and quantified using CIE L*a*b* color space. RESULTS: The correlation between the CIE $b^{*}$-value and urine osmolality $\left(r_{s}=0.89\right)$ was determined to be significantly $(p=0.004)$ greater than the correlation between the subjective 8-point urine color scale and urine osmolality $\left(\mathrm{r}_{\mathrm{s}}=0.85\right)$. The correlation between the CIE $\mathrm{b}^{*}$-value and USG $\left(\mathrm{r}_{\mathrm{s}}=0.90\right)$ was also determined to be significantly $(\mathrm{p}<0.001)$ greater than the correlation between the urine color chart and USG $\left(\mathrm{r}_{\mathrm{s}}=0.84\right)$. Lastly, the correlation between urine color as determined by the 8-point subjective urine color chart and the CIE $b^{*}$-value had a strong relationship $\left(r_{s}=0.92\right)$. Conclusions: The correlations of the quantitative CIE $b^{*}$-value with urine osmolality and USG were significantly greater than the correlations with the 8-point subjective urine color scale. This suggests that a quantitative measurement of urine color via spectrophotometry is a better measure for assessing hydration status vs. subjective determination of urine color. The results of the current study raise the possibility of spectrophotometry as an additional non-invasive method of determining hydration status.
\end{abstract}

Keywords: Urine Color, Urine Osmolality, CIE L*a*b* Color Space, Dehydration

\section{Introduction}

Urine color $\left(\mathrm{U}_{\mathrm{col}}\right)$ has been previously examined as a potential indicator of hydration status by comparing it to several established laboratory measures including urine specific gravity (USG) and urine osmolality. USG and urine osmolality are objective measures of the concentration of dissolved solutes within urine. A subjective measure of $U_{\text {col }}$ has been developed in which a sample is assessed using an 8point color scale where the number identifies the level of hydration [1]. Although practical and easy to use, the chart's ability to predict changes in hydration has been inconsistent. Studies have shown that $U_{c o l}$ measured by a subjective urine color chart can, in some cases, be a valid indicator of hydration status in specific populations, such as young, male athletes and elderly women [2-9]. However, the relationship between subjective urine color and standard methods of determining hydration has overall shown variable results [7,

\section{0-12].}

For example, the relationship between $\mathrm{U}_{\text {col }}$ and USG were measured from daily urine samples for eight weeks from Caucasian nursing home residents $(\mathrm{N}=98)$ [7]. It was found that females $(\mathrm{N}=40)$ had a significant correlation $(\mathrm{r}=0.67, \mathrm{p}<$ $0.01)$ between $U_{\text {col }}$ and USG, while males $(\mathrm{N}=38)$ did not $(\mathrm{r}=0.17, \mathrm{~ns})$. There also was a significant correlation between $\mathrm{U}_{\mathrm{col}}$ and USG in all females while only males with adequate renal function had a significant, but weak, correlation $(\mathrm{r}=0.39)$. This suggests that the relationship between $\mathrm{U}_{\mathrm{col}}$ and USG varies depending on sex and renal function. As this study was only conducted in a Caucasian, elderly population, the effects of ethnicity and age on the $U_{\text {col }}$ chart's relationship to USG remains unclear. Adams et al. [13] also found that there were significant differences in $\mathrm{U}_{\text {col }}$ measures between males and females. Additionally, Fortes et al. [10] took a convenience urine sample in adults, 60 years and older, $(\mathrm{N}=130)$ upon admission to a hospital and participants were 
placed into groups depending on their hydration status. They found that the urine color scale was unable to discriminate between dehydration and euhydration. They suggest that this was due to decreased renal function common in older adults or that a potential confounding factor of their medication affected the urine color. These results suggest that subjective assessments of $U_{\text {col }}$ are not a reliable method of assessing dehydration.

Numerous studies [2-11] have used subjective measures of $\mathrm{U}_{\mathrm{col}}$ to help predict hydration status, but only one [14] has used objective measures of $U_{\text {col }}$ to measure hydration status. Using the CIE $\mathrm{L}^{*} \mathrm{a} \mathrm{b}^{*}$ color space Zhang et al. [14] found that a strong correlation exists between the $b^{*}$-value and urine osmolality $(\mathrm{r}=0.86, \mathrm{p}<0.0001)$. The $\mathrm{L}^{*}$-value $(\mathrm{r}=-0.56$, $\mathrm{p}<0.0001)$ and $\mathrm{a}^{*}$-value $(\mathrm{r}=-0.35, \mathrm{p}<0.0001)$ also had significant, but weak, correlations with urine osmolality. Although they found that quantified $U_{\text {col }}$ had a strong correlation to urine osmolality, they did not measure $\mathrm{U}_{\mathrm{col}}$ on the 8-point subjective scale. Thus, it is unknown if the objective $\mathrm{U}_{\text {col }}$ was better at predicting hydration status than the simpler, but more subjective 8-point scale.

In light of the above, the purpose of this study was to compare the subjective 8-point urine color scale and the objective method of CIE L*a*b* color space to see which was a better measure of hydration status. It is hypothesized that the objective assessment of $U_{\text {col }}$ will have a stronger correlation to established standard measures of hydration status than the subjective assessment of $\mathrm{U}_{\mathrm{col}}$.

\section{Methods}

Prior to data collection, all subjects read and signed an informed consent approved by the San Diego State University IRB. Participants ( $\mathrm{N}=28,6$ female and 22 male) provided 151 spot samples of urine over several days. The mean \pm SD age was $28.6 \pm 11.3$ and $29 \%$ considered themselves not Caucasian. Urine osmolality was measured in duplicate using a Wescor (Logan, UT) model 5500 vapor pressure osmometer and USG was measured using a clinical refractometer. Subjective $U_{\text {col }}$ was determined by two investigators using the Armstrong et al. 8-point urine color scale [1]. Objective $U_{\text {col }}$ was measured using a HunterLab Vista spectrophotometer and quantified on the CIE L*a*b* color space. Briefly, this three-dimensional color space consists of the $\mathrm{L}^{*}$-value which measures lightness of a sample, with " 100 " being the lightest it can be and " 0 " being the darkest. The $\mathrm{a}^{*}$-value measures between green and red, the negative values indicating more green and the positive values indicating more red. The $b^{*}$-value measures between blue and yellow, the negative values indicate blueness and the positive values indicate yellowness. For both $a^{*}$ - and $b^{*}$ values, " 0 " indicates an absence of the colors on its axis. Relationships between the variables were determined using Spearman rank correlations. Correlations were compared according to the procedures outlined by Eid et al. [15].

\section{Results}

USG and urine osmolality, the well-established standards of measuring whole body hydration status, exhibited a strong relationship $\left(\mathrm{r}_{\mathrm{s}}=0.97\right)$ (Table 1$)$. The 8-point scale [1] and urine osmolality also had a strong relationship $\left(r_{s}=0.85\right)$ (Figure 1), but urine osmolality had a stronger correlation with the CIE $b^{*}$-value $\left(r_{s}=0.89\right)$ (Figure 2$)$. It was determined that these two correlations were significantly different from one another $(\mathrm{p}<0.004)$. The USG had a strong correlation to the 8-point color scale $\left(\mathrm{r}_{\mathrm{s}}=0.84\right)$, but had a stronger correlation with the $\mathrm{b}^{*}$-value $\left(\mathrm{r}_{\mathrm{s}}=0.90\right)$ (Table 1$)$. These correlations were also deemed significantly different from one another $(\mathrm{p}<0.001)$. There was also a strong relationship between the $b^{*}$-value and 8-point urine color scale $\left(r_{s}=0.92\right)$ (Figure 3).

\section{Discussion}

The results of the current study illustrate that both subjective (i.e., 8-point urine color scale) and quantitative (i.e., CIE L*a*b* color space $b^{*}$-value) measures are significantly correlated to established measures of hydration (i.e., urine osmolality and USG), as seen in Figures 1 and 2. Figure 3 also illustrates the strong, positive relationship between the values obtained from the 8-point color chart and the CIE $b^{*}$-value. These results agree with past studies that have found a strong relationship between 8-point urine color chart and urine osmolality and USG [2-9].

The subjective $U_{c o l}$ results agree with past research findings in the literature. Armstrong et al. found strong correlations between $\mathrm{U}_{\text {col }}$ using the 8-point subjective scale and urine osmolality $\left(\mathrm{r}^{2}=0.77\right)$ and USG $\left(\mathrm{r}^{2}=0.80\right)$ in a homogenous sample of young, healthy women [2]. Hahn \& Waldréus studied men and women with a wide age range (ages 17-69) and found that the urine color scale had a moderately strong correlation to USG $(\mathrm{r}=0.73)$ as well as to osmolality $(\mathrm{r}=0.73)$ [3]. Kavouras et al. found that selfassessment of $U_{\text {col }}$ in children's 24-hr collection had a positive relationship with urine osmolality $\left(\mathrm{r}^{2}=0.45, \mathrm{p}<\right.$ 0.001) [4]. In women, even those pregnant and lactating, Mckenzie et al. [6] found that 24-hour $\mathrm{U}_{\text {col }}$ was significantly correlated to 24-hour urine osmolality $(\mathrm{r}=0.61-0.84$, all $\mathrm{p}<$ $0.001)$ and 24-hour USG ( $r=0.62-0.89$, all $\mathrm{p}<0.001)$. Mentes et al. [7] examined elderly caucasian men and women and found that the women with adequate renal function had a moderately strong relationship between $U_{\text {col }}$ and USG $\left(r_{\mathrm{s}}=0.67\right)$.

The current results agree with the above findings. However, it was additionally determined that although the qualitative 8-point urine color scale has a strong relationship to urine osmolality $\left(r_{\mathrm{s}}=0.85\right)$ and USG $\left(\mathrm{r}_{\mathrm{s}}=0.84\right)$, the quantitative measurement of the CIEL*a*b* colorspace $b *$ value has stronger relationships to osmolality $\left(r_{s}=0.89\right)$ and USG ( $\left.r_{\mathrm{s}}=0.90\right)$.

Among the three quantitative parameters of urine color, we found the $b^{*}$-value had the strongest correlation to both USG and urine osmolality, thus the $\mathrm{b}^{*}$-value is the most 
meaningful in predicting hydration status. This makes sense as the $b^{*}$-value represents the change in color on a scale from yellow to blue while the $a^{*}$-value represents the change in color from green to red and the $\mathrm{L}^{*}$-value represents how much lightness or darkness is in the color. The differences in color depend on the collective change of these three values.
As the only other study that we know of that used CIEL*a*b* colorspace, Zhang et al. also found a strong correlation between the $\mathrm{b}^{*}$-value and urine osmolality $(\mathrm{r}=0.86, \mathrm{p}<0.0001)$, where the $\mathrm{b}^{*}$-value also showed good sensitivity $(97.4 \%)$ and specificity $(65.6 \%)$ [14].

Table 1. Spearman Rho correlation table for urine osmolality, urine specific gravity (USG), 8-point urine color chart, $L^{*}$-value, $a^{*}$-value, and $b^{*}$-value.

\begin{tabular}{lllllll}
\hline Characteristic & $\begin{array}{l}\text { Urine Osmolality } \\
\text { (mmol/kg) }\end{array}$ & $\begin{array}{l}\text { Urine Specific } \\
\text { Gravity (g/mL) }\end{array}$ & $\begin{array}{l}\text { 8-Point Urine Color } \\
\text { Scale (units) }\end{array}$ & $\begin{array}{l}\mathbf{L}^{*} \text {-value } \\
\text { (units) }\end{array}$ & $\begin{array}{l}\mathbf{a}^{*} \text {-value } \\
\text { (units) }\end{array}$ & $\begin{array}{l}\mathbf{b}^{*} \text {-value } \\
\text { (units) }\end{array}$ \\
\hline Urine Osmolality (mmol/kg) & 1.00 & 0.97 & 0.85 & -0.70 & -0.55 & 0.89 \\
Urine Specific Gravity (g/mL) & 0.97 & 1.00 & 0.84 & -0.77 & -0.52 & 0.90 \\
8-Point Urine Color Scale (units) & $0.85^{*}$ & $0.84^{* *}$ & 1.00 & -0.74 & -0.57 & 0.92 \\
L $^{*}$-value (units) & -0.70 & -0.77 & -0.74 & 1.00 & 0.37 & 0.83 \\
$\mathrm{a}^{*}$-value (units) & -0.55 & -0.52 & -0.57 & 0.37 & 1.00 & -0.63 \\
$\mathrm{~b}^{*}$-value (units) & $0.89^{*}$ & $0.90^{* *}$ & 0.92 & 0.83 & -0.63 & 1.00 \\
\hline
\end{tabular}

* Indicates correlations were significantly different from each other $(\mathrm{p}<0.05)$.

** Indicates correlations were significantly different from each other $(\mathrm{p}<0.05)$.

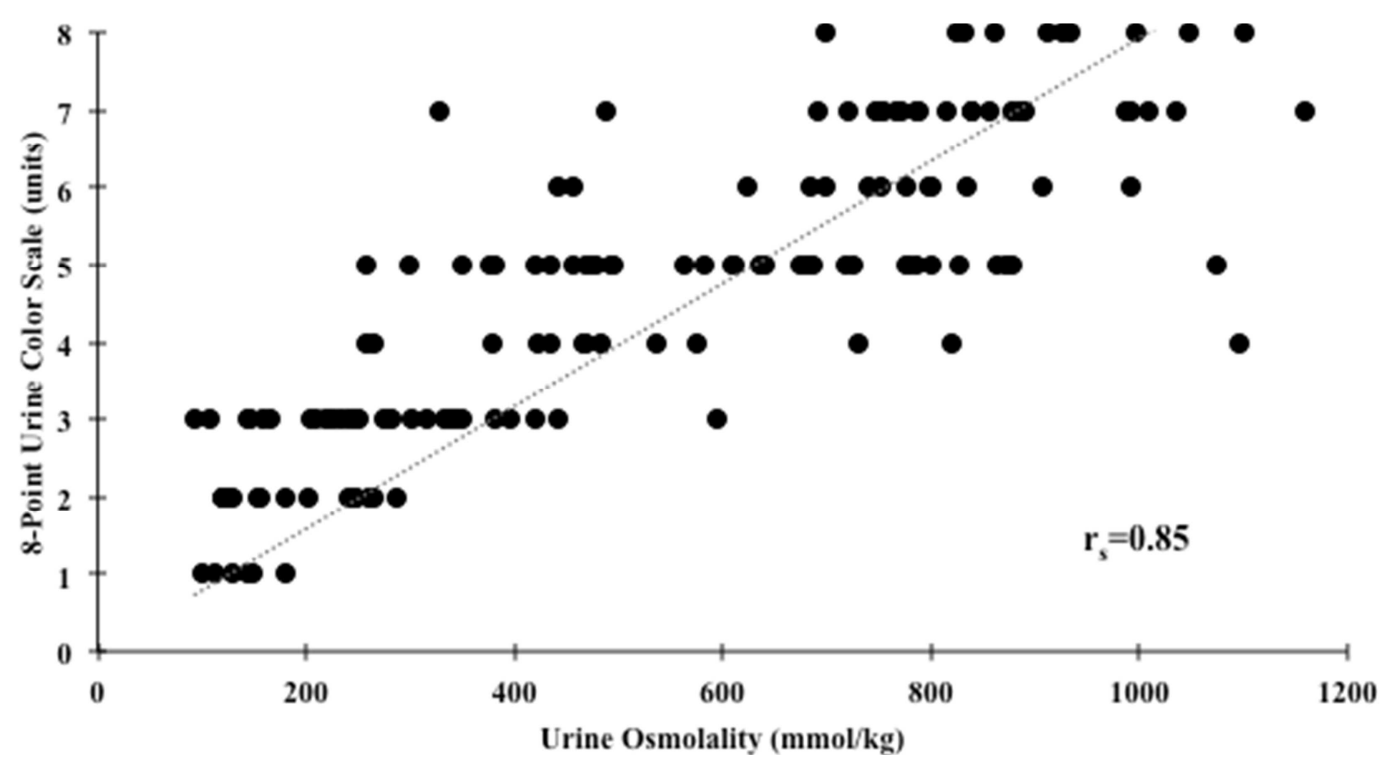

Figure 1. Correlation between urine osmolality (mmol/kg) and the 8-point urine color chart.

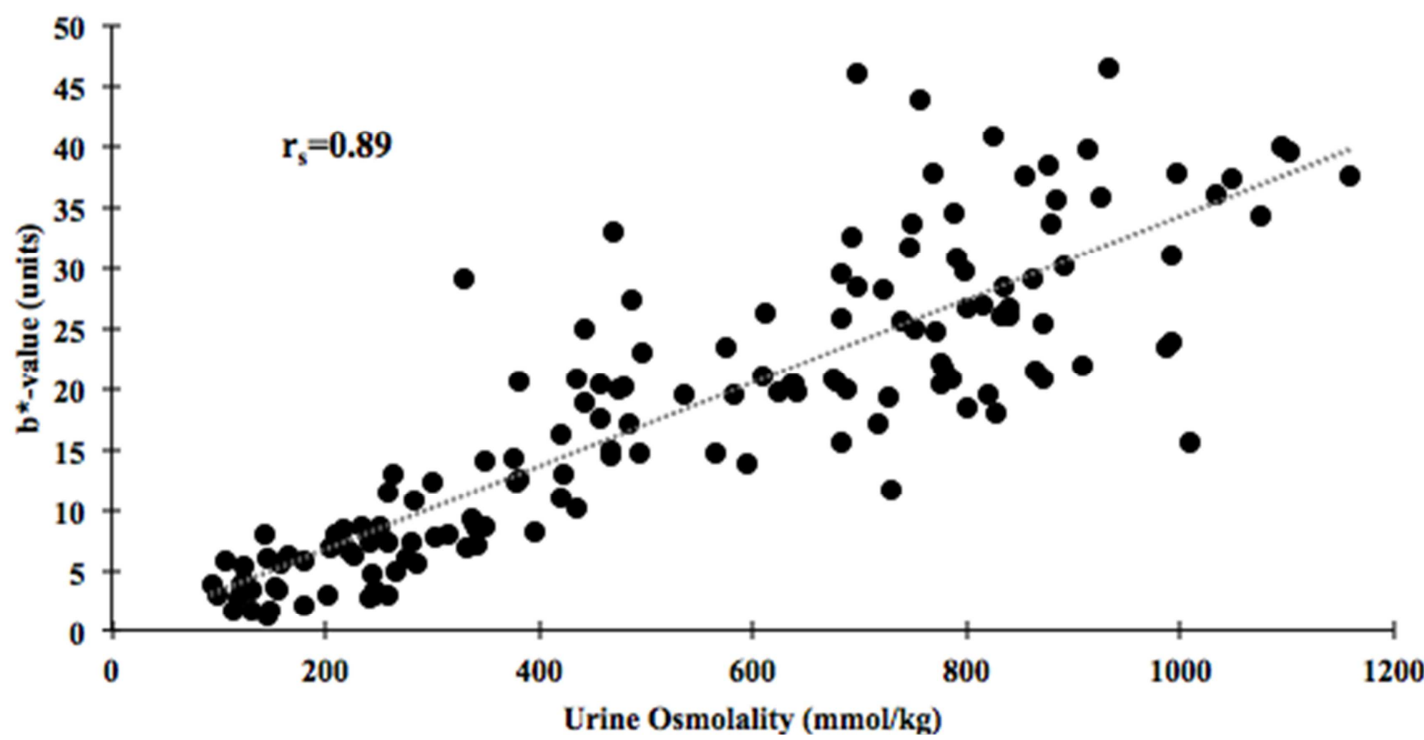

Figure 2. Correlation between urine osmolality (mmol/kg) and the $b^{*}$-value. 


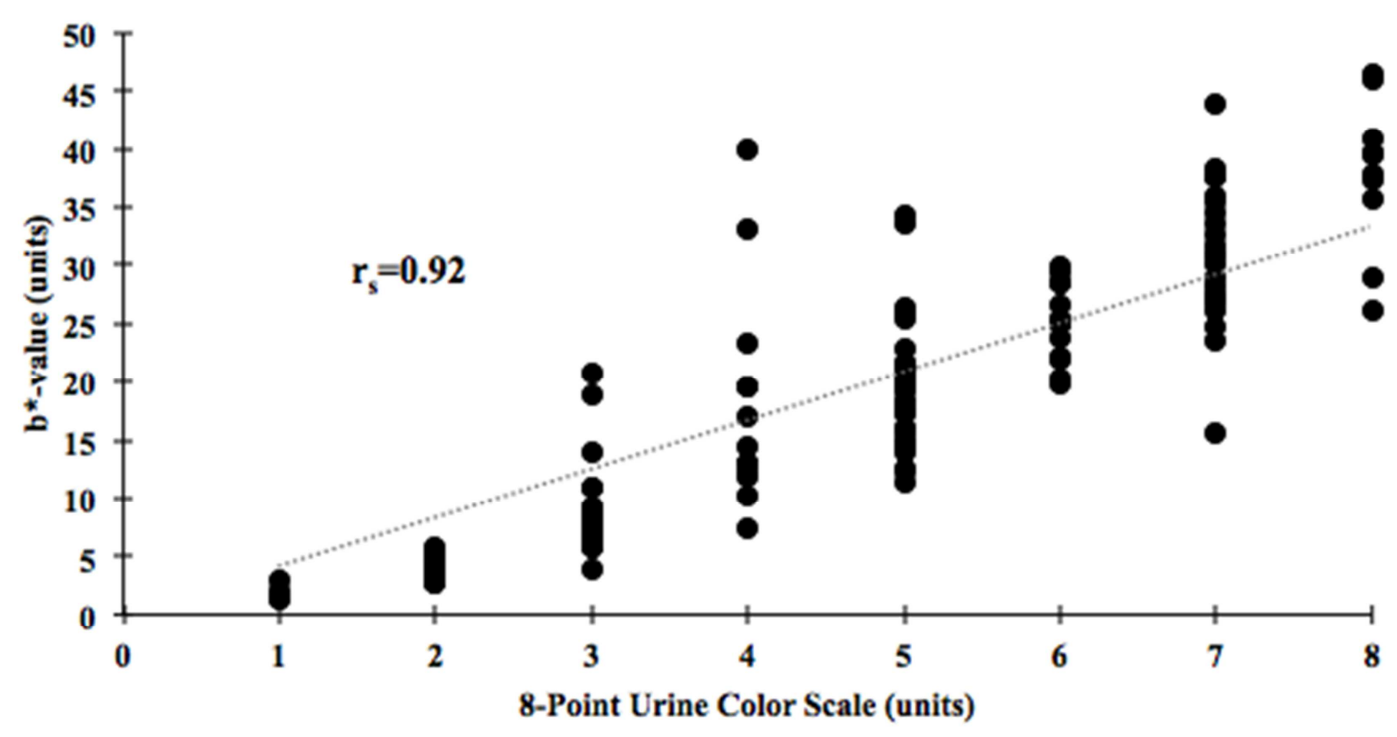

Figure 3. Correlation between the 8-point urine color chart and the $b^{*}$-value.

The current study has several weaknesses. First, the study utilized free living conditions relevant to real world situations over several days, thus factors that might affect urine color (e.g., diet, medications, liver disease, kidney disease, etc.) were not controlled. Second, these findings require replication with a larger and more diverse sample.

In conclusion, the positive relationship between the objective parameters at assessing hydration suggests that a subjective assessment of urine is accurate. However, the correlation of the $b^{*}$-value with osmolality and USG were greater than the correlation with Armstrong ratings. This suggests that a quantitative measurement through multispectral analysis is more accurate at determining hydration status than the qualitative urine color chart. These results raise the intriguing possibility of spectrophotometry as an additional non-invasive method of determining hydration status.

\section{Conclusion}

The objective measure of the $b^{*}$-value has a stronger correlation with osmolality and USG than the subjective measure of the urine color chart. These results suggest the possibility of a quantitative measure of urine color as a determinant of hydration status.

\section{References}

[1] Armstrong, L. E., et al. (1994). Urinary indices of hydration status. International Journal of Sport Nutrition, vol. 4, no. 3, 1994, pp. 265-279., doi: 10.1123/ijsn.4.3.265.

[2] Armstrong, L. E., Johnson, E. C., Munoz, C. X., Swokla, B., Bellego, L. L., Jimenez, L., Casa, D. J., \& Maresh, C. M. (2012). Hydration biomarkers and dietary fluid consumption of women. Journal of the Academy of Nutrition and Dietetics, 112 (7), 1056-1061. doi: 10.1016/j.jand.2012.03.036.
[3] Hahn, R. G., \& Waldréus, N. (2013). An aggregate urine analysis tool to detect acute dehydration. International Journal of Sport Nutrition and Exercise Metabolism, 23 (4), 303-311. doi: 10.1123/ijsnem.23.4.303.

[4] Kavouras, S. A., Johnson, E. C., Bougatsas, D., Arnaoutis, G., Panagiotakos, D. B., Perrier, E., \& Klein, A. (2015). Validation of a urine color scale for assessment of urine osmolality in healthy children. European Journal of Nutrition, 55 (3), 907-915. doi: 10.1007/s00394-015-0905-2.

[5] Armstrong, L. E., Pumerantz, A. C., Fiala, K. A., Roti, M. W., Kavouras, S. A., Casa, D. J., \& Maresh, C. M. (2010). Human hydration indices: acute and longitudinal reference values. International Journal of Sport Nutrition and Exercise Metabolism, 20 (2), 145-153. doi: 10.1123/ijsnem.20.2.145.

[6] Mckenzie, A. L., \& Armstrong, L. E. (2017). Monitoring body water balance in pregnant and nursing women: the validity of urine color. Annals of Nutrition and Metabolism, 70 (1), 18-22. doi: 10.1159/000462999.

[7] Mentes, J. C., Wakefield, B., \& Culp, K. (2006). Use of a urine color chart to monitor hydration status in nursing home residents. Biological Research For Nursing, 7 (3), 197-203. doi: $10.1177 / 1099800405281607$.

[8] Hasibuan, D., Ramayani, O., Sembiring, T., \& Lubis, M. (2019). Relationship between urine color scale and urine specific gravity to hydration status in elementary school students. Global Journal For Research Analysis (GJRA), 8 (9). doi: $10.36106 /$ gjra.

[9] Mckenzie, A. L., Muñoz, C. X., Ellis, L. A., Perrier, E. T., Guelinckx, I., Klein, A.,... Armstrong, L. E. (2015). Urine color as an indicator of urine concentration in pregnant and lactating women. European Journal of Nutrition, 56 (1), 355362. Doi: $10.1007 / \mathrm{s} 00394-015-1085-9$.

[10] Fortes, M. B., Owen, J. A., Raymond-Barker, P., Bishop, C., Elghenzai, S., Oliver, S. J., \& Walsh, N. P. (2015). Is this elderly patient dehydrated? Diagnostic accuracy of hydration assessment using physical signs, urine, and saliva markers. Journal of the American Medical Directors Association, 16 (3), 221-228. doi: 10.1016/j.jamda.2014.09.012. 
[11] Kovacs E. M., Senden J. M., \& Brouns F. (1999). Urine color, osmolality and specific electrical conductance are not accurate measures of hydration status during postexercise rehydration. J Sports Med Phys Fitness, 39: 47-53.

[12] Cheuvront, S. N., Ely, B. R., Kenefick, R. W., \& Sawka, M. N. (2010). Biological variation and diagnostic accuracy of dehydration assessment markers. The American Journal of Clinical Nutrition, 92 (3), 565-573. doi: 10.3945/ajen.2010.29490.

[13] Adams, W. M., Hevel, D. J., Maher, J. P., \& Mcguirt, J. T. (2020). Racial and sex differences in 24 hour urinary hydration markers among male and female emerging adults: a pilot study. Nutrients, 12 (4), 1068. doi: 10.3390/nu12041068.

[14] Zhang, N., Du, S., Zheng, M., Tang, Z., Yan, R., Zhu, Y., \& Ma, G. (2017). Urine color for assessment of dehydration among college men students in Hebei, China-a cross-sectional study. Asia Pacific Journal Clinical Nutrition, 788-793.

[15] Eid, M., Gollwitzer, M., \& Schmitt, M. (2011). Statistik und forschungsmethoden lehrbuch. Weinheim: Beltz. p. 548 . 